\title{
Managerialismo versus Prácticas Locales. La decolonización del discurso managerial desde la vida de la Escuela*
}

\author{
Managerialism versus Local Practices. The decolonization of the managerial discourse from within schools'life \\ Managerialismo versus práticas locais. A descolonização do discurso managerial a partir da vida da Escola
}

\author{
Vicente Sisto ${ }^{\text {a }}$ \\ Pontificia Universidad Católica de Valparaiso, Chile \\ vicente.sisto@pucv.cl \\ ORCID: http://orcid.org/0000-0003-4510-4041
}

DOI: https://doi.org/10.11144/Javeriana.cao32-58.mvpl Redalyc: http://www.redalyc.org/articulo.oa $? \mathrm{id}=20560207004$

Fecha de recepción: 27/09/2018

Fecha de aprobación: 29/03/2019

Fecha de publicación: 30/06/2019

\section{Resumen:}

Bajo el patrocinio de organismos internacionales y think tanks, el Managerialismo se ha instalado como racionalidad técnica única para pensar el organizar en Latinoamérica, silenciando otros modos de hacer organización. El proceso de 'modernización’ neoliberal impulsado por la Dictadura de Pinochet constituyó a Chile en un caso emblemático. El presente artículo se propone mostrar cómo, a pesar de la violencia con la cual se impone este modelo, persisten prácticas que dan cuenta de otras formas de construir una vida conjunta. Mediante datos producidos en el campo escolar chileno, fuertemente intervenido por políticas managerialistas, se muestra cómo emergen, en los intersticios, prácticas mediante las cuales se expresan otras formas de organizar, basadas en la comunidad, cooperación y solidaridad.

Códigos JEL: D73, L38, M54

Palabras clave: Estudios organizacionales críticos, Decolonialidad, Gestion, Trabajo Docente.

\section{Abstract:}

Under the support of international organizations and think tanks, the Managerialism have gradually been installed as a unique technical rationality to think about organizing in Latin America, silencing other ways of doing organization. Chile has been an emblematic case. It is from this place that this paper aims to show how, despite the violence with which this model is imposed, practices that show other ways of building a life together persist. Through data produced in the Chilean school system, it is exposed how other practices emerge in the interstices. Practices that show other ways of organizing, based on community, cooperation and solidarity.

JEL Codes: D73, L38, M54

Keywords: Critical organizational studies, Decoloniality, Management, Teaching Work.

\section{Resumo:}

Sob o patrocínio de organizações internacionais e think tanks, o managerialismo foi instalado como a única racionalidade técnica para pensar a gestão na América Latina, silenciando outras maneiras de fazer organização. O processo neoliberal de "modernização" promovido pela ditadura de Pinochet constituiu o Chile em um caso emblemático. Este artigo tem como objetivo mostrar como, apesar da violência com que esse modelo é imposto, persistem práticas que dão conta de outras formas de construção de uma vida conjunta. Através de dados produzidos no campo da educação chilena, fortemente intervido por políticas managerialistas, mostrase como surgem nos interstícios práticas através das quais são expressas outras formas de organização baseadas na comunidade, a cooperação e a solidariedade.

Códigos JEL: D73, L38, M54

Palavras-chave: estudos organizacionais críticos, Descolonialidade, Gestão, Trabalho Docente.

Notas de autor: 


\section{Introducción}

En las últimas décadas, Latinoamérica ha sido impactada por diversas interpelaciones a la cotidianeidad con miras a promover al managerial ismo como el mejor modo de organizar y al emprendedor como el mejor modo de ser, favoreciendo individualización, privatización y eficientismo en las relaciones sociales. Tanto desde las políticas públicas fuertemente guiadas por organismos internacionales (Fardella, Sisto, Morales, Rivera \& Soto, 2016; Pereira, 2010; Varela, 2018), como desde la industria cultural (Castillo, 2011; Maguiña, 2007), se ha ofrecido insistentemente la imagen del gerenciamiento de la empresa privada como la forma más eficiente de organización colectiva. Si bien la instalación de este referente ha sido de modo parcial y discontinuo en el espacio latinoamericano, sí se ha logrado constituir como un modelo para la acción colectiva y para las formas de identidad social, instalándose con violencia - militar y/o cultural- por sobre los modos de organizar y ser de América Latina. Tal como señaló Mignolo (2016), los procesos de modernización de nuestras sociedades han seguido de modo ciego las directrices racionalizadoras, impulsadas bajo lógicas modernizantes eurocéntricas. Éstas han tenido en el managerialismo un modo concreto de penetrar en los espacios organizativos cotidianos imponiendo individualismo y eficientización de los modos de acción colectiva por sobre otros modos de hacer que fueron negados y borrados.

Chile ha sido considerado como un país emblemático en la instalación y promoción de modelos manageriales del organizar, en un contexto de profunda flexibilización y precarización laboral. Esto desde 1975, cuando las llamadas "Siete Modernizaciones" impulsadas por el dictador Pinochet se instalaron con el fin de transformar la economía, el Estado y la sociedad, bajo los principios neoliberales propuestos por Hayek, Friedman, Buchanan, entre otros (Fischer, 2009). Estas reformas interpelaron la acción del estado en su conjunto con la desregulación de las relaciones laborales, y promoviendo privatización, competencia y rendición de cuentas como parte fundamental de la acción pública. La empresa privada se instala como modelo de gestión, y el emprendedor como ideal de sujeto a ser promovido desde la acción del Estado. El advenimiento de la democracia no cambió esto. Por el contrario, bajo el amparo de los organismos internacionales, los nuevos gobiernos democráticos reforzaron, mediante políticas públicas, estas lógicas ya instaladas a fuerza de sangre por el Dictador ( Cornejo, González, Redondo, Sánchez, \& Sobarzo, 2011; Schild, 2007; Sisto, Montecinos, \& Figueroa, 2013; Stromquist \& Sanyal, 2013). Diversos estudios han mostrado cómo formas organizativas basadas en relaciones cooperativas, varias vinculadas a prácticas populares y orientadas a la construcción de lo común fueron acorraladas bajo la acción de políticas públicas que reinscribieron la acción local bajo el lenguaje de la gestión eficiente de la empresa privada (de la Maza, 2004; Fardella, Sisto, Morales, Rivera \& Soto, 2016; Oxhorn, 2004; Sisto, 2012).

Es desde este lugar que se escribe este artículo; un lugar en el cual ya desde hace más de 40 años se ha instalado - con la violencia de la dictadura y luego con la sutileza de la socialdemocracia-, la lógica managerial con su racionalidad acalladora como directriz de las formas de acción conjunta. Sin embargo, a pesar de ello persisten prácticas que se desarrollan como murmullos en los intersticios, y que día a día construyen otras formas de cuestionar la gramática managerialista. He ahí el interés de este escrito. Se espera mostrar cómo persisten prácticas que dan cuenta de otras formas de construir una vida conjunta, a pesar de la violencia con la cual se impone el managerialismo como corporización de las lógicas coloniales contemporáneas (Abdalla \& Faría, 2017). Esto implica cuestionar no sólo los modelos de gestión dominantes, sino también las orientaciones críticas que emergen desde el espacio europeo y anglosajón, las que, si bien han dado cuenta de los modos de reproducción del neoliberalismo y las prácticas de resistencia que emergen, han tendido a mantener una lectura dual basada en la polaridad reproducción/resistencia, sin abordar cómo en esos espacios de resistencia, así como en los intersticios de las prácticas cotidianas, se construyen otros modos de organizar y de hacer conjuntamente. En este contexto de urgencia, es necesario ir más allá, tener oídos para escuchar unos susurros que se cuelan entremedio de esos espacios de reproducción y resistencia... y que hoy están invisibilizados. 
Para ello, este artículo presentará ciertos datos de investigación producidos en la Escuela chilena con el fin de ilustrar tanto la instalación ahogante de lógicas manageriales, como la persistencia y la reconstrucción que los actores hacen cotidianamente sosteniendo formas de acción y de vida conjunta inimaginadas por estas lógicas administrativas. La Escuela, instalada en Latinoamérica como parte del proyecto de modernidad, se ha desplegado mediante prácticas híbridas caracterizadas por saberes, identidades y formas de construir vida en común que han emergido localmente constituyendo cotidianamente el espacio escolar (AdlersteinGrimberg, 2017; Contreras-Salinas, 2012; Huergo \& Morawicki, 2010; Sisto, Montecinos, \& Figueroa, 2013. Este espacio ha sido fuertemente intervenido durante las últimas dos décadas mediante diversos instrumentos y estrategias que buscan obligar a la Escuela a actuar managarialmente, con una intensidad no vista hasta ahora (Bruns, Filmer, \& Patrinos, 2011; Jennings, 2010; Sisto, 2012 Escribir desde este espacio de construcción organizativa cotidiana nos permitirá abordar la violencia con la cual se están imponiendo lógicas managerialistas en espacios locales. Pero, a la vez, nos permitirá acercarnos a prácticas que emergen cotidianamente, y construyen otro modo de organizar, bajo lógicas diferentes a las manageriales emprendedoras. En este contexto, hablar desde ciertas experiencias de investigación permitirá mostrar algunas orientaciones y herramientas que pueden colaborar en un investigar atento a aquello que se construye desde los intersticios.

\section{Managerialismo como corporización de las lógicas coloniales contemporáneas}

Durante la década de 1980, las técnicas, prácticas y valores derivados de la gran empresa privada comenzaron a instalarse como referentes únicos del organizar. Este será asociado a una acción individual -del gerente y/o líder- que moviliza a otros para el logro de una mayor efectividad, produciendo resultados claramente tangibles y medibles, en un contexto de competencia con otras organizaciones -comunidades y/o colectivos-. Eficiencia, efectividad y excelencia suelen ser señalados como objetivos fundamentales, para lo cual las organizaciones deben desarrollar procesos de mejora continua. Junto a lo anterior, se recomiendan estrategias de gestión basadas en competencias y administración por objetivos, así como tercerización, contratos por tarea o servicios, y salarios dependientes de resultados, promoviendo lógicas de carrera de tipo emprendedor (Sisto, 2012; Thomas \& Davies, 2005. A esto se le denomina Managerialismo, caracterizado por un discurso legitimador que, bajo la forma de lo técnico y 'apolítico', se instala dogmáticamente como la única forma de gestión posible (Parker, 2002. Este modelo de pensamiento, promovido por Escuelas de Management, pero también por organismos internacionales y think tanks, prontamente se instala como una idea casi incuestionable: todo -incluyendo organismos públicos, cooperativas, organizaciones comunitarias, entre otros- deben ser gestionadas como empresas privadas (Gunter, 2008; Hodge \& Coronado, 2006; Parker, 2002.

Tal como han mostrado autores como Barba (2015, Gentili (1998, Mato (2007, Ortiz-Gómez (2014 y Pereira (2010, entre otros, en Latinoamérica la acción de los organismos internacionales fue fundamental en esta naturalización del managerialismo como racionalidad, supuestamente técnica y neutral. La crisis económica de la década de 1980 empujó a los países Latinoamericanos a contraer endeudamiento, con lo cual organismos multilaterales, tales como el Banco Mundial, el Fondo Monetario Internacional, y Banco Interamericano de Desarrollo incrementaron su peso político. La transferencia monetaria de fondos que realizaron estos organismos, vino acompañada de prescripciones acerca de cómo debía potenciarse el desarrollo de los países y sus comunidades, instalando sus modelos como verdad ineludible, interpelando particularmente a la administración del estado y a la acción pública. Así, desde la década pasada los informes de organismos internacionales insistían en un elementos clave (Shah, 2005: la necesidad de reformar el Estado, transformar su estructura, descentralizando e incorporando proveedores privados de servicios públicos, los cuales podrían ser financiados mediante mecanismos de financiamiento basadas en cumplimiento de 
objetivos y resultados; instalando la competencia entre proveedores estatales descentralizados y privados, como garante de calidad. Esto implica la aplicación de sistemas de rendición de cuentas, basados en cumplimiento de estándares y resultados, a los cuales queda condicionado el financiamiento (Shah, 2005).

Si bien cada país aplicó estas prescripciones de modo heterogéneo y con diversa intensidad, la impronta managerialista se ha hecho presente de un modo generalizado en Latinoamérica (Pereira, 2010). Incluso en aquellos países en los cuáles se instalaron gobiernos progresistas, algunos declarados como 'antineoliberales', los mismos procesos de recuperación de derechos sociales que les caracterizó se han realizado mediante estrategias basadas en la privatización y en la responsabilización individual por resultados, promoviendo competencia incluso al interior de los servicios públicos, sostenido esto como la mejor estrategia posible (Hypolito, 2011; Sierra, 2011). Esto muestra la fuerza con la que el managerialismo se ha ido imponiendo paulatinamente en Latinoamérica. La imposibilidad de pensar incluso el fortalecimiento del Estado y de los derechos fuera de la premisa managerial es una muestra de cómo el lenguaje, categorías, prescripciones y valores del managerialismo se instalan como verdad incuestionada.

Tal como ha señalado Treynor (2012), la imposición del managerialismo en los diversos espacios debe ser comprendida como una historia de colonización. Puede haber menos brutalidad, pero el dolor y la confusión acompañan las actividades evangelizadoras de aquellos que traen esa visión proclamada como única e incuestionable, visión que "encuentra sus orígenes distantes pero vívidos en el descubrimiento de la razón por la Ilustración que se apoderó del pensamiento, la imaginación y la aspiración europeas en el siglo XVIII" (p. 2). La colonialidad, "la cara más sombría de la negación del otro... [hoy está siendo reinventada] por medio de procesos hegemónicos de construcción y universalización del neoliberalismo y de la matriz cultural-científica eurocéntrica” (Abdalla y Faría, 2017, p. 917). Esto se aprecia especialmente en cómo los modelos de gerenciamiento se instalan -promovidos por 'expertos'- desconociendo otros saberes y prácticas, reinterpretándolas, silenciándolas y/o apropiándose de ellas, subalternizándolas, mediante diversos mecanismos de consentimiento y coerción. Por ello, siguiendo a Treynor "cuando digo colonización, pretendo preguntar hasta qué punto el lenguaje gerencialista y las categorías de pensamiento que éste ha puesto, borrando otros, han logrado establecerse como el lenguaje dominante" (Treynor, 2012, p. 12).

La promoción del managerialismo como única alternativa posible del organizar se afirma en una retórica sustentada en descripciones factuales que muestran como algo indiscutido la necesidad de cambiar, señalando que de no hacerlo, los países y sus comunidades serán arrastrados a la pobreza y al subdesarrollo (Sisto \& Fardella, 2011). En este discurso supuestamente avalado en una evidencia científica, el 'cambio' es presentado como homogéneo y natural, donde objetos, dispositivos y personas hacen parte de una misma dimensión, en un mismo tipo de proceso (Sisto \& Zelaya, 2013; Sisto, 2017). La creación y universalización de rankings globales, instrumentos, modelos y métodos, ha favorecido que cualquier problema social, en cualquier parte del mundo, pueda ser clasificado como un "problema de gestión" por las instituciones nacionales e internacionales y los llamados 'expertos'; diagnóstico que deja en claro cuál es la solución: más management (Abdalla y Faría, 2017).

\section{Chile y su Escuela como Espacio de instalación managerial}

Chile ha sido considerado un caso particular en el cual la instalación del predominio managerialista en la comprensión del organizar se desarrolló de un modo anticipado al fuerte impulso que esto recibió desde mediados de la década de 1980 (Harvey, 1989). Desde 1974, con el inicio de las llamadas Siete Modernizaciones se comenzó a instalar una verdadera Revolución Neoliberal al amparo de la violencia de la dictadura militar de Pinochet. La desregulación laboral y arancelaria, así como el comienzo de la privatización de la economía, fueron los primeros rasgos de esta reforma, que prontamente tocaría a los mismos cimientos del Estado. Kast (1983), Ministro de Planificación Nacional, explicando la política del gobierno de Pinochet, 
señalaba que la mejor forma de organizar al Estado y a sus políticas de desarrollo social, era disminuyendo el tamaño del Estado, transformándolo en uno de tipo subsidiario, y externalizando una serie de sus funciones tales como la educación, previsión e implementación de políticas sociales, instalando sistemas de competencia y financiamiento según resultados, como mecanismo para lograr mayor eficacia y eficiencia.

Con la llegada de la democracia, esta lógica no concluirá. Si bien se generarán algunas amortiguaciones a los efectos negativos de este sistema (como el Plan Auge, la mejora de las pensiones asistenciales y el subsidio de cesantía, entre otros, este sistema será más bien perfeccionado, instalando nuevos dispositivos, en un contexto global en el cual los organismos internacionales precisamente están promoviendo el tipo de reformas que Chile ya había iniciado (Fardella, 2013; de la Maza, 2004.

Uno de los campos en los cuales esto se ha expresado de un modo extremo ha sido en el de la educación (Assaél et al., 2011; Fardella, 2013. En este ámbito, desde 1980, mediante la Ley General de Educación se inicia una profunda transformación. El primer elemento refiere a la descentralización del sistema traspasándose la administración de las escuelas a las municipalidades, incorporando además prestadores privados de servicios educativos. Privados y municipales compiten en el ámbito de la captación de matrículas, bajo un modelo de financiamiento basado en el subsidio a la demanda, conocido como Voucher. Este modelo de financiamiento fue conceptualizado por Milton Friedman hace ya más de 50 años, como una estrategia para incrementar la calidad educativa, y mejorar el control del gasto público. Esto, en el contexto de una privatización radical de los servicios educativos, de modo que la competencia emerge como el principal estímulo para mejorar la calidad. Con ello Chile realizó la instalación de proveedores privados de servicios educativos en competencia con los públicos bajo modelos de financiamiento basados en el subsidio a la demanda antes que el Banco Mundial recomendara estas medidas como garante de calidad (p. ej., Banco Mundial, 1996; Bruns, Filmer, \& Patrinos, 2011; Shah, 2005.

Desde 1990, con la asunción de la Concertación de Partidos por la Democracia al gobierno, se inició una reforma educativa orientada a transformar el curriculum, a la vez que a mejorar las condiciones materiales y didácticas con las que trabaja la escuela, entre otros. Sin embargo, desde el año 2000, siguiendo el llamado de los organismos internacionales, se comenzó a implementar una segunda ola de reformas. Enfocados en la gestión educativa, se desarrollaron estándares de desempeño para directores (Marco de la Buena Dirección y docentes (Marco de la Buena Enseñanza que regulan procesos de formación, selección y evaluación. Las mediciones de calidad ya existentes, como el SIMCE (Sistema de Medición de Calidad Educativa, basado en un test de aprendizaje en lenguaje y matemáticas, pasaron a tener un rol fundamental en el financiamiento, desarrollo y/o cierre de escuelas mediante la Ley de Subvención Preferencial (Ley 20.248 de 2008. Ésta entrega un voucher adicional a las Escuelas, por cada estudiante vulnerable, en función de compromisos de desempeño con altas consecuencias, entre ellas el cierre de la Escuela si no logra mejoras sustantivas en los resultados de pruebas estandarizadas, medida que luego se replicará en el llamado Sistema de Aseguramiento de Calidad. Paralelamente se desarrollan políticas orientadas a favorecer la función directiva, y mejorar el desempeño individual de los profesores en función de estándares.

Con relación a los Directores, se incorporaron sistemas de selección en función de su experticia en gestión, instalando la concursabilidad en función de méritos evaluados por una comisión de expertos en gestión, no por la comunidad; pudiendo postular además cualquier profesional del área administrativa con experiencia en educación. Estos directores son evaluado y premiados en función de los resultados en el SIMCE de la Escuela. Además, a lo largo de las últimas reformas, incluyendo la Ley de Carrera Docente, se aumentaron las prerrogativas, constituyéndolos en verdaderos gerentes de las escuelas, en consonancia con la idea de que una organización funciona mejor si su gerente -líder- es eficiente y efectivo (Sisto, 2010 y 2018.

Además se implementó un sistema de evaluación e incentivos al desempeño docente según cumplimiento de estándares, a través de tres etapas distintas. La primera es obligatoria (Evaluación Docente, y las siguientes son voluntarias: AVDI (Asignación Voluntaria de Desempeño Individual y AEP (Asignación de Excelencia Pedagógica. El éxito en cada una de ellas está asociado a incentivos económicos individuales. El haber 
rendido exitosamente la AEP le permite, además, al profesor acreditarse como un Maestro de Maestros, con lo cual puede dejar horas de clases para desarrollar consultorías a otros profesores que hayan obtenido malos resultados en la evaluación, y a otras escuelas, en el contexto de las tareas propias de la Ley de Subvención Escolar Preferencial, trabajo por el cual son remunerados. Éste es señalado como el ícono de desarrollo profesional que debiese inspirar a la profesión docente.

Este mecanismo fue potenciado mediante la llamada Ley de Carrera Docente, promulgada el año 2016 (Ley 20.903). Ésta amplia el ámbito de aplicación de los estándares de desempeño docente hacia la formación que realizan las universidades, de modo que sus currículos deben orientarse a formar de acuerdo con estos estándares, lo que es "asegurado" entrenando a los estudiantes para obtener buenos resultados en estas mediciones. Un segundo elemento que caracteriza a esta Ley es que, si bien mantiene los instrumentos, aumenta las consecuencias de los resultados. El llamado portafolio es el instrumento en el cual recae prácticamente todo el peso de la calificación. Éste exige al docente presentar evidencia de lo que sería su mejor práctica pedagógica, a lo cual se añade la videograbación de una clase realizada por un equipo del Ministerio. Este material es revisado por personal técnico con formación en educación o ciencias sociales, cuyo trabajo es aplicar rúbricas que permiten establecer los niveles de logro de esos desempeños en función de los estándares, sin necesariamente conocer la Escuela, o el contexto del trabajo pedagógico específico. A partir de esto se "encasilla" al profesor en un tramo de desempeño, situando al profesor en una estructura salarial, e incluso, estableciendo quiénes pueden ser despedidos y quienes -los de “buen desempeño”- pueden guiar a los nuevos profesores que ingresan.

La instalación de sistemas de evaluación de desempeño individual y sistemas de selección de directores basados en experticia técnica más que en función de su vínculo con la comunidad, el desarrollo de mecanismos de rendición de cuentas vinculados a resultados, todas medidas que, a juicio del Banco Mundial, hacen trabajar a la Escuela (Bruns, Filmer, \& Patrinos, 2011). Así el Estado, a través de sus diferentes gobiernos, de izquierda y de derecha, ha sostenido una línea altamente coherente, interpelando, mediante sus legislaciones, a la Escuela como una organización que debe ser gestionada como empresa para alcanzar resultados medidos por indicadores $^{[1]}$.

Tal como se aprecia, la política educativa chilena, particularmente aquella desarrollada durante las últimas dos décadas, expresa la impronta del Nuevo Management Público, desplegando los supuestos propios del paradigma funcionalista dominante en Management, como fundamentos incuestionados de las políticas: (a) el trabajo de una organización puede ser segmentado en actividades individuales; (b) éstas deben ser administradas a partir de una cabeza central: la gerencia; (c) la gerencia debe liderar, buscando mantener la coherencia en la organización en torno a los objetivos, controlando los focos de divergencia, heterogeneidad y disenso, integrando estos a la mirada establecida desde la gerencia; (d) por otra parte, la calidad de los desempeños individuales depende de las competencias que tenga el individuo para realizar esos desempeños; (e) estas competencias pueden ser medidas con eficacia mediante adecuados procesos de selección que consideren mérito; (f) los buenos desempeños individuales pueden ser estimulados mediante incentivos económicos; (g) el Gerente es el responsable de todos los procesos al interior de la organización, y por lo tanto del éxito de la organización; (h) la conducción organizacional es, finalmente, una práctica individual.

Esto se instala sobre una organización que, si bien fue creada como concreción del proyecto modernista de racionalizar a las masas, mediante la educación, se organizó en el espacio latinoamericano mediante otras prácticas muy diferentes a aquellas racionalizadoras, mostrando a la escuela como un espacio no sólo de colonización sino de continua decolonización. Tal como ha señalado Mignolo (2016), en Latinoamérica todo el despliegue de la acción colonizadora en sus diversos momentos se ha realizado a la par que la continua acción decolonizadora que se realiza desde los espacios locales. En Latinoamerica la Escuela se ha desarrollado en la frontera entre institución que lleva a cabo parte fundamental del proyecto modernizante educando a las masas para ser insertadas en dicho proyecto y espacio fundamental para la construcción de lo común desde lógicas populares no coloniales (Núñez-Muñoz, Solis-Araya, Soto-Lagos, 2017), desarrollándose a 
través de prácticas solidarias y cooperativas propias de las culturas populares latinoamericanas a pesar de los procesos de formalización institucional que pesan sobre ella (Adlerstein-Grimberg, 2017; Contreras-Salinas, 2012; Sisto, Montecinos, \& Figueroa, 2013. Es este espacio fronterizo el que hoy se encuentra bajo el asedio managerialista que se instala como única forma de gestionar posible, instalación que busca ser asegurada mediante mecanismos de evaluación y rendición de cuentas con altas consecuencias para la escuela, y sus personas, en un contexto de competencia y financiamiento según resultados y cumplimiento de estándares.

\section{La escuela contra las versiones managerialistas del organizar: estudiar la decolonización como práctica}

Diversos trabajos han señalado cómo la mirada crítica en ciencias sociales ha tendido a mantener los análisis en torno a las formas de dominio, incluido el managerial, al interior de la dicotomía reproducción vs. resistencia, sin profundizar cómo, en ciertas prácticas de resistencia se despliegan otros modos de hacer las cosas, otros modos de construir el trabajo, la organización y la sociedad. Los trabajos de Scott (2009, en diversos contextos asiáticos, así como los trabajos más recientes de autores como Fúnez-Flores y Phillion (2019, en contextos educacionales multicultares, y Manning (2018, en diversos contextos organizacionales, han coincidido en mostrar cómo perspectivas de investigación críticas suelen quedar atrapadas en dicha dicotomía, produciendo datos y etiquetando las prácticas locales bajo las categorías de reproducción/ resistencia o incluso, en el campo laboral, bajo la dicotomía trabajo prescrito/trabajo realizado, sin abordar cómo en esas 'resistencia' o esas acciones 'realizadas' más allá de lo prescrito, llevan consigo además otro modo de construir organización que no siempre se logra articular explícitamente para los actores, pero que se sostiene y actúa en sus prácticas cotidianas. He ahí que Fúnez-Flores y Phillion (2019 toman el llamado realizado por de Sousa Santos (2015 y 2018 para desplegar lo que denomina una sociología de las ausencias y de las emergencias. En efecto "¿Por qué tanto conocimiento, tantas prácticas quedan ausentes, no son visibles, no son creíbles en nuestras vidas? ... Inexistencias, invisibilizar, ocultar" (de Sousa Santos, 2018, p. 6. Es esto lo que hace la retórica managerial, y sus instrumentos, que traducen el acontecer cotidiano del organizar a su lenguaje, acallando otras maneras de hacer las cosas; dejando a los hablantes sin recursos ni categorías para describir y explicitar aquello que realizan en los intersticios del predominio managerial... y que sostiene buena parte del trabajo cotidiano, en nuestro caso, de la Escuela.

Las epistemologías del Sur, al producir esta sociología de las ausencias, sociologías invisibles, abren camino para la sociología de las emergencias. Es honrar las luchas de estos hombres y de estas mujeres, que con tanta sabiduría nunca renuncian a luchar por una vida digna, en las peores condiciones. El entusiasmo que vemos en nuestros talleres, en los movimientos, que siguen luchando, divirtiéndose y cantando y bailando y bebiendo, porque la vida no es solamente la lucha. Y nosotros, si queremos captar esas emergencias, ¿cómo vamos a hacer? ¿con las armas de la sociología, de la antropología? No, no me parece. Nuestras metodologías son extractivistas. Hablamos de que la minería es extractivista, pero nosotros hacemos lo mismo en nuestras universidades. Nosotros no queremos el conocimiento de la gente; la gente nos da información, no nos da conocimiento. El conocimiento nosotros nos lo damos. No es ecología del saber, es extractivismo. (de Sousa Santos, 2018, p 6)

En efecto, lo que 'coleccionamos' en el campo empírico lo clasificamos bajo nuestras categorías prescritas, leemos 'resistencia', leemos 'trabajo realizado', pero no leemos que ahí mismo están fluyendo también otros modos de construir organización a los cuales los practicantes no le han puesto palabras, pero que lo realizan día a día en sus prácticas cotidianas. En efecto esas otras versiones de hacer organización, de hacer Escuela, hablan a través de las labores de sus practicantes, de los trabajadores y comunidades que día a día construyen el educar como una ocurrencia cotidiana. Por ello Fúnez-Flores y Phillion (2019) llaman a rechazar la universalización y estandarización en la producción de conocimiento en el campo educativo, para atender a aquello que parece excluido o silenciado, como un intento pragmático de descubrir la diversidad de conocimientos que está luchando para ser visibilizado y escuchado. Con ello el lugar de la teoría y la metodología de las 
ciencias sociales, gran parte producida en contextos anglosajones y eurocéntricos, es el de la herramienta, una herramienta que permite abrir el espacio social y tener oídos para aquello que no es audible y que va más allá de nuestras categorías: "podemos llevar nuestras teorías, pero para traer otras" (de Sousa Santos, 2018, p. 6).

Desde hace aproximadamente una década vengo realizando investigaciones, entre otros campos, en organizaciones escolares, en tanto caso emblemático de implantación de políticas manageriales en el Chile contemporáneo. Un interés ha sido comprender cómo están implantándose de modos prácticos estas lógicas manageriales en esos espacios locales, pero también como las comunidades escolares traducen, resisten y transforman aquello que es impuesto. Tal como se ha podido apreciar, la Escuela no se subordina fácilmente, y emergen otras versiones del organizar a través de las prácticas que realizan individual y conjuntamente (Sisto, 2012; Sisto, Montecinos, \& Ahumada, 2013; Sisto, 2018). Es a partir de estos resultados de investigación que esperamos mostrar cómo la Escuela, como espacio fronterizo, en su devenir cotidiano, contesta al managerialismo que se le impone, desplegando en las fisuras otros modos de hacer organización.

Tal como indican Fúnez-Flores y Phillion (2019), así como de Sousa Santos (2018), el trabajo investigativo, centrándose en las prácticas cotidianas, ha buscado abrirse a la ocurrencia concreta y heterogénea del hacer conjuntamente, a esa otredad múltiple que se despliega en el día a día (Fardella, Sisto, Morales \& Rivera, 2016; Sisto 2012; Sisto, 2018). Las principales herramientas fueron:

a) Etnografias orientadas a la práctica, abordando las relaciones cotidianas de los actores de la comunidad (docentes, directivos, funcionarios, apoderados y estudiantes) entre sí, y con los contextos, herramientas e instrumentos con los cuales se vinculan, incluyendo dispositivos de gestión y otros (Fardella et al., 2016; Sisto et al., 2008). Se adoptó una perspectiva etnometodológica vinculada a los estudios de la práctica que ha desarrollado la investigadora italiana, con años de vida y trabajo en Latinoamérica, Silvia Gherardi (2015), y reelaborada en la práctica investigativa local (Sisto \& Zelaya, 2013). Esto permite indagar en cómo se van construyendo los actores, en la interacción cotidiana, cómo son moldeadas las agendas individuales y conjuntas, cómo son negociadas contingentemente las prácticas legítimas y las que no lo son, cómo se construye un escenario (un mundo) que demanda ciertas acciones para los actores y prohíbe otras, y cómo, bajo qué procesos, estas construcciones son modificadas.

b) Entrevistas situadas de carácter activo reflexivo (Fardella, 2013; Sisto 2012). La entrevista debe ser concebida como una interacción en la cual los partícipes son reconocidos como sujetos, entrevistador/ a y entrevistada/o. Es desde una interacción viva, en la cual se reconocen los diversos posicionamientos de los partícipes, que se construye el texto de la entrevista. Estas propuestas las hemos desarrollado en el campo del trabajo generando entrevistas reflexivas situadas en el espacio laboral (Fardella, 2013; Sisto, 2008). La entrevista como espacio dialógico permite una reflexividad conjunta del hacer en el trabajo, suspendiendo las certezas y aquello naturalizado.

Para cada caso estos datos, fueron discutidos con los actores locales, así como con profesores de movimientos docentes, desarrollando procesos de análisis colaborativo que permitieron fortalecer los procesos de interpretación, abriendo además discusiones críticas en torno a las políticas y prácticas de gestión en la Escuela. A partir de esto, en los apartados siguientes, intentaremos revisar y repensar brevemente dos campos en los cuales la mirada managerialista de la Escuela como organización ha influido drásticamente: liderazgo, con sus nociones en relación a cómo debe dirigirse la Escuela, y trabajo docente, con los sistemas de evaluación, incentivo y desarrollo que se desprenden de ello. 


\section{¿Liderazgo? Del Individuo a la Acción Conjunta}

Cuando el mandato managerial indica que el buen desempeño de la Escuela se basa en un director, que como líder individual es capaz de infundar visión y compromiso en sus seguidores (la comunidad escolar, la Escuela responde que, si bien la posición directiva provee de prerrogativas relevantes, en cuanto a que su posición formal permite facilitar o no ciertas relaciones y ciertas prácticas, no es el director el responsable del devenir de la Escuela. Eso que denominan mejora o buen desempeño de la Escuela, no es obra del Director, sino de la construcción conjunta que realiza una comunidad.

Las siguientes citas corresponden a una Escuela de una comuna semi-rural de la zona centro sur de Chile:

Cita 1:

Cuando llegamos a la Escuela había muchas madres y padres varios estaban trabajando en el jardín -cuidando planta, podando árboles- con profesores, funcionarios, y niños. Una profesora me explicó que, por la hora, varios habían ido a buscar a sus hijos y que se quedaban conversando... y que era normal que colaboraran en hacer cosas de la Escuela. Pude conversar con una mamá y me dijo que siempre que podía, con otras mamás o papás, cuidaban a la escuela... pues es "su espacio" (...) Luego, una profesora me hizo entrar a la Sala de Profesores, donde ya se realizaba el Consejo, y estaban todos en círculo. No era claro quienes eran de la "Dirección”... al preguntar, me indican que la Directora está sentada a un lado, entremedio de otros profesores, así como el resto de la Dirección, todos repartidos. En ese momento están dialogando en torno a una tarea para el Ministerio, y es un profesor -que no es miembro formal de la dirección- el que da los turnos y hace síntesis de lo que van hablando. (Cuaderno de Campo)

Cita 2:

"(Luego del terremoto del 2010) lo primero que hicimos fue visitarnos los unos a los otros, primero los profesores, luego nos dividimos entre nosotros (profesores) y visitamos a todas las familias. Algunos (apoderados y profesores) habíamos perdido nuestras casas, pero otros tenían espacio y nos podían recibir... es que entre todos tenemos que hacer esto, entre todos tenemos que ayudarnos". (Entrevista a Profesora)

Cita 3:

"Nuevamente el Ministerio de Educación me asigna a mí el premio (monetario) por el (buen) desempeño de la Escuela. Nosotros les hemos pedido que repartan esto por igual entre los profesores. Esto lo hacemos todos. Pero no. iTercer año consecutivo! Los años anteriores igual lo recibí yo (el incentivo), y lo repartimos... pero este año acordamos que ya no! Esto es un asunto de dignidad. Así que lo rechacé!" (Entrevista a Directora)

Estas tres citas ilustran una lógica de hacer las cosas, de "dirigir" que se opone a la mirada managerialista que insiste en instalar la política pública, según la cual es el individuo -el gerente- el responsable por los éxitos o fracasos de la organización. Estas citas, recogidas en el contexto de un trabajo de campo realizado entre 2010 y 2011, no son una anomalía y confirma lo que ya había señalado el Informe de Evaluación del Impacto de la Política Sistema de Aseguramiento de la Calidad elaborado para el Ministerio de Educación (Sisto, et al., 2008), en la cual se investigaron etnográficamente 10 escuelas distintas de todo Chile, escogidas en conjunto con el Ministerio en función de su posibilidad de representar la heterogeneidad de las Escuelas públicas municipales chilenas. La observación práctica de cómo se organizan a nivel cotidiano las escuelas que, según el Ministerio, logran mejoras sostenidas a largo plazo en sus diversos indicadores, revela que éstas tienden a funcionar organizacionalmente de un modo mucho más semejante a las organizaciones sociales de los años 80, tales como ollas comunes u otras agrupaciones cooperativas autogestionadas que emergieron en procesos de resistencia a la dictadura, que a las empresas privadas desde donde se han extraído los modelos de liderazgo individualizado que tienden a promocionarse como los más efectivos para todas las organizaciones (Sisto et al., 2008). Investigaciones recientes obtienen datos similares (Fardella, Sisto, Morales, Soto \& Rivera 2016; Sisto, 2015). Es curioso que, a pesar de que una de las pocas evaluaciones de impacto que ha realizado el Ministerio sobre sus políticas de gestión señale elementos opuestos a los principios manageriales, este dogma se imponga, sin hacer caso a lo que se construye día a día en la Escuela. El dogma de esta nueva evangelización no requiere justificación. 
Tal como se puede apreciar en las citas, la presencia del nosotros es fundamental. La dirección de procesos específicos es distribuida, como ilustran las notas del cuaderno de campo al referirse al Consejo de Profesores. La Escuela se constituye en espacio común, espacio de cuidado mutuo cooperativo y solidario, apreciable tanto en los arreglos del jardín, como en relación a la acogida de quienes se quedaron sin casa post terremoto. Este nosotros curiosamente es interrumpido por la interpelación a un yo que hace la política al ofrecer un incentivo monetario al yo individual de la Directora, mostrando cómo la política constituye al Director/Directora como responsable individual por mejoras o buenos desempeños de la organización (Escuela), merecedora, por lo tanto incentivos monetarios individuales. Da igual que la propia organización solicite ser interpelada (y premiada) como un nosotros. No se puede vulnerar el dogma.

He ahí que podemos ver cómo la gramática managerial, a través de sus instrumentos, intenta inscribir su lenguaje en el espacio cotidiano que se construye conjuntamente. A pesar de ello, no lo logra. La Escuela sostiene otras formas de acción irreconocibles e impensables bajo las categorías del managerialismo. Mirar la Escuela como un espacio que se construye a partir de articulaciones parciales, donde el trabajo es visto como un accionar conjunto, supone no sólo una noción diferente de liderazgo, sino que también de trabajo docente.

\section{El trabajo docente más allá del desempeño individual (según estándares)}

Si el mandato managerial indica que el trabajo docente debe ser concebido como un desempeño individual de estándares comportamentales 'objetivamente' esperables para todos los casos y lugares, y debe ser medible aplicando rúbricas a muestras de desempeño individual aisladas de su contexto, la práctica concreta del trabajo docente realizado en Escuelas, responde que, si bien lo que hace cada profesor es fundamental, la acción de cada uno emerge desde un espacio conjunto. Por ello el trabajo docente debe pensarse más como una articulación, un hacer cotidiano, manifiesto en lo que los profesores hacen individual y conjuntamente respondiendo a una complejidad incapaz de ser abordada por estándares.

Las siguientes citas emergen de trabajo de campo y de 50 entrevistas realizadas entre 2010 y 2016 , referidas al proceso de evaluación docente que hoy es central en política de carrera docente.

Cita 4:

"(La evaluación) me pareció punitiva. Porque te... yo la encuentro subjetiva. Porque, ¿en qué sentido? Porque yo puedo desarrollar... para mis ojos está bien, pero para las personas que te van a fiscalizar a lo mejor no está bien. A lo mejor las personas que te van a evaluar y que están en la comisión, a pesar de que tienen tiempo de preparación, a lo mejor no han vivido la experiencia del nivel, no tienen la realidad del curso, entonces es subjetivo de como ellos te pueden evaluar". (Entrevista a Profesora de 52 años)

Cita 5:

"Como yo nunca me había evaluado. ella igual manejaba como eh: ciertas cosas poh. Por ejemplo, eh, pillerías, igual, así como bueno tu acá tienes que poner tal palabra porque a ellos eso es lo que les gusta escuchar (...) Acá decía por ejemplo, no sé poh, iNo, esta palabra NO! cámbiala por tal cosa porque esa palabra si engloba, y me dio primeras ideas como de estrategias que ella maneja porque es profesora de básica que yo, yo no manejo (...) Eso fue como fundamental... porque si no..." (Entrevista a Profesora de 40 años)

Cita 6:

Hoy llegaron los del Ministerio a grabar la clase del Profesor ZZ. Cuando nos acercamos nos dimos cuenta que los niños de esa clase -de entre 8 y 10 años- llegaron todos especialmente peinados y vestidos. Les preguntamos a los niños si el Director o el Profesor les habían pedido venir arreglados. Y nos dijeron que no, que lo hacían porque hoy evaluaban a su profesor: "es nuestro profe! Hay que defenderlo!" (Cuaderno de Campo)

\section{Cita 7}

"Pero ¿cómo modificarlo [el Sistema de Evaluación Docente]? es la pregunta del millón. Hay una alta tendencia depresiva en esta época, hay gente que no duerme, se trastorna, es todo un estrés; el tiempo no alcanza, o sea, tú tienes que hacerlo después de las horas de trabajo y (con propiedad), por ejemplo, para mí, el lunes yo trabajé con mi curso en sexto cuatro horas, después me tocó un primero básico, y nombro este curso porque es demandantes al 100\%, después un tercero básico que 
también son chicos demandantes... yo terminé agotada. Hoy ya para mí es un día agotador y después de eso, tomar los libros para sentarte y empezar a tratar de trabajar. A mí me costó, esta vez me costó mucho... porque llego cansada, llego agotada, yo lo único que quiero es mi cama, descansar unos minutos para descansar mi mente”. (Entrevista a Profesora de 52 años)

\section{Cita 8}

(¿Qué es un buen profesor?) "Un buen profesor, creo que es como, en el fondo, motivar lo más posible a los estudiantes a despertar, digamos, a tener una conciencia de su entorno, a participar activamente, a ayudar a sobrellevar, digamos eh, todas las miserias que produce este sistema o este modelo en términos eeeh.. de vida, como también en términos intelectuales, cachay (entiendes)?, sobre todo cuando tu alumno es una persona súper popular, que, que está dominado por una serie de prejuicios, y que vive reproduciendo esos prejuicios, por ejemplo, prejuicios contra la mujer, contra la nacionalidad de otro compañero, cachay?, todo, el arribismo, y por eso también, y a través de eso también, que sea una persona capaz de crear también, capaz de, de:: despertar y generar algo nuevo.

También, el hecho de poder estar polemizando y problematizando continuamente, tu forma de ejercitar, ser muy autocrítico, ir siempre proponiendo nuevas cosas, generar los espacios de convergencia con tus colegas de otros tipo de disciplina, también para ir enfrentando las problemáticas". (Entrevista a profesor de 40 años)

Estas citas de entrevistas y notas de cuadernos de campo, sirven, como collage, para mostrar distintas imágenes acerca de cómo se construye el trabajo docente día a día, y cómo el instrumento de evaluación docente se instala en ese espacio local.

La primera cita (cita 4) es de una profesora que recibió la más alta calificación que puede otorgar el sistema: destacada. Sin embargo a pesar de ello insiste en que la evaluación es punitiva. Lo interesante de la cita, tal como fue trabajada en un escrito previo (Sisto, 2012), es que vincula lo punitivo a que "la encuentro subjetiva". Lo que se explica señalando que, lo que "para mis ojos está bien, pero para las personas que te van a fiscalizar a lo mejor no está bien", describiendo a los que "te van a fiscalizar" o "que te van a evaluar y que están en la comisión", como personas que "tienen tiempo de preparación", pero que no tienen "la experiencia del nivel, no tienen la realidad del curso". Por ello, "entonces es subjetivo de como ellos te pueden evaluar". De este modo se opone la 'preparación', es decir, la lógica experta, versus el conocimiento situado de la realidad del grupo curso y del nivel, de lo cual los docentes son conocedores. Es por ello que esta política, basada en estándares de desempeño, emerge como subjetiva, pues responde a otros criterios "alejados del curso y del nivel; en definitiva, de la escuela” (Sisto, 2012, p. 42). Es en este contexto que se califica como punitiva, pues castiga ese conocimiento local.

Tal como se puede apreciar el rechazo a la política conlleva otra versión de trabajo docente que es distinta a la ofrecida por los expertos, 'preparados' y sus estándares.

Las citas 5 y 6 dan cuenta del despliegue cotidiano en un contexto de evaluación docente. El portafolio individual es construido colaborativamente; y esta colaboración puede incluir estudiantes también. Esto muestra cómo el trabajo docente resulta mucho más interconectado que lo que supone la política, incluso a la hora de enfrentar al propio instrumento.

La cita 7 resulta clave pues emerge de la misma entrevista de la cual fue extraída la cita 4. Se le ha preguntado a la participante acerca de cómo cambiar el sistema de evaluación. Efectivamente ella, en la cita 4, da cuenta de la relevancia de "la experiencia del nivel", sin embargo a la hora de confrontar directamente cómo podría ser otro sistema de evaluación, su relato la lleva a hablar del estrés que le provoca la evaluación. Esta narrativa, si bien permite denunciar que el sistema no está bien, que daña al docente, por otra parte no permite articular una respuesta explícita. Esta cita es representativa del corpus. En efecto, frente a la posibilidad de articular otra versión explícita, los hablantes tendieron a relatar dolor y malestar, terminar en la cama y dormir, inhabilitados. He aquí como la ausencia y lo emergente aparecen juntos en la misma entrevista. En la cita 4 sí hay una crítica que indica la distancia entre la prescripción y la práctica cotidiana, sin embargo, a la hora de responderle a la política, queda el estrés y el silencio.

A diferencia de ello, la cita 8 , si bien no refiere a la evaluación en sí, indica de modo explícito qué es lo relevante para el ejercicio del trabajo docente, conectando con la cita 4. Aquí la pedagogía deja de ser un desempeño instruccional orientado por estándares y abocado a resultados, sino que emerge como una relación 
con el otro orientada hacia la justicia y transformación social, tanto hacia el estudiante, como con los colegas, problematizando y creando cosas nuevas "generando espacios de convergencia".

\section{Conclusiones}

Mediante este escrito me he enfocado en cómo el managerialismo, como un discurso dominante acerca del organizar, se impone sin considerar espacios ni prácticas locales. Se impone con una violencia dogmática, mediante, instrumentos, prescripciones, rankings, condicionando financiamientos y estabilidad laboral de los actores locales, con el fin de que se disciplinen bajo la doctrina managerial. El proceso evangelizador managerialista incluso pasa sobre la racionalidad eurocéntrica que podría exigir evidencias acerca de si esto funciona o no. El dogma vale por sí mismo, y las masas deben ser convertidas. Sin duda esto no es un tema de mejor o peor gestión, estamos frente a un proceso de imposición cultural que reclama borrar otras posibilidades de organización común. El managerialismo, disfrazado de neutralidad y racionalidad técnica, ha impuesto su orden individualizador y desarticulador sobre las distintas esferas de la vida social, lo que se ha expresado con fuerza en política educativa. Siguiendo a Marañon:

La palabra descolonialidad hace referencia a las luchas y prácticas sociales orientadas a desmantelar la dominación y la explotación propias del patrón de poder actual, de modo que se extienda la reciprocidad entre individuos, que contribuya a la desmercantilización del trabajo y la vida, que se abran espacios para el autogobierno...” (Marañon, 2016, p. 12)

Las prácticas que despliegan cotidianamente las escuelas y sus comunidades precisamente dan cuenta de otra forma de construir vida en común, que se oponen al proyecto cultural dominante, donde aún la comunidad persiste como eje de la acción. Aquí se aprecia lo señalado por Dussel (2001), en el sentido de que, la política, como práctica cotidiana, consiste en el arte de construir una vida en común, donde el punto de partida es la comunidad.

Los estándares establecidos para medir el desempeño docente, si bien pueden ser considerados una guía orientadora de carácter abstracto, al concretarse mediante un sistema de medición que clasifica a los profesores, se distancia dramáticamente de lo que es el trabajo real y concreto que realizan conjuntamente en las comunidades escolares, debilitándolo, especialmente en los sectores vulnerables.

Las revisiones de Sanabria-Rangel, Saavedra-Mayorga y Smida (2015) así como también Gantman (2017), señalan que la investigación organizacional crítica en Latinoamérica ha tendido a orientarse más a cómo se instalan dispositivos de dominación sobre el espacio del trabajo y cómo el orden neoliberal es reproducido en los espacios organizacionales más que a comprender cómo en esos espacios organizacionales cotidianos también emergen prácticas que sostienen otras formas de organizar, basadas en otros referentes comunitarios y cooperativos. De acuerdo con Ibarra-Colado, el deber de los estudios organizacionales críticos en América Latina sería "estudiar las consecuencias que el orden burocrático y las instituciones del mercado han producido en realidades que se edificaron históricamente bajo modos de racionalidad distintos sustentados en la organización comunitaria y la solidaridad" (Ibarra-Colado, 2006, p. 103). Estos modos no sólo persisten, sino que son transformados cotidianamente por los actores. Ante la fuerza con la que se instala el managerialismo, fuerza garantizada por instrumentos que interpelan de modo muy directo la cotidianeidad de los actores, éstos, individual y conjuntamente, no sólo reproducen aquello prescrito, junto con ello establecen otras formas de acción que sí pueden ser vistas como resistencia, pero que además conllevan otras versiones del organizar, del hacer Escuela. Si Mignolo ha señalado que "el pensamiento decolonial emergió en la fundación misma de la modernidad/colonialidad, como su contrapartida” (Mignolo, 2016, p. 10). Nosotros diremos que la práctica decolonial emerge constantemente en los intersticios mismos de la modernidad/colonial/ managerial como su constante contrapartida. Desde ese punto de vista el rol de una investigación crítica consiste en abrirse a atender a esas prácticas que no siempre alcanzan a ser articuladas bajo una voz legítima, 
pero que persisten innombradas e inimaginadas incluso para sus propios practicantes. He aquí nuestra responsabilidad.

\section{Agradecimientos}

La investigación contó con el apoyo del Fondo Nacional para el Desarrollo de la Ciencia y la Tecnología (FONDECYT, Proyecto 1191015; el Programa de Investigación Asociativa del Consejo Nacional de la Ciencia y la Tecnología de Chile (CONICYT PIA/CIE 160009 y el Proyecto Núcleo Milenio Autoridad y Asimetrías de Poder, de la Iniciativa Científica Milenio del Ministerio de Economía, Fomento y Turismo (Chile.

\section{Referencias}

Adlerstein-Grimberg, C. (2017. Aportes de Néstor García Canclini y Paulo Freire a la superación de la perplejidad educativa. Paulo Freire, 6, 39-49.

Assaél, J., Cornejo, R., González, J., Redondo, J., Sánchez, R., \& Sobarzo, M. (2011. La empresa educativa chilena. Educ. Soc. Campinas, 32(115, 305-322

Banco Mundial (1996: Prioridadesy estrategiaspara la educación: examen del Banco Mundial. Washington DC: Banco Mundial.

Barba, C. (2015. Los enfoques latinoamericanos sobre la política social: más allá del Consenso de Washington. Espiral. Estudios sobre Estado y Sociedad, 31, 85-130.

Bruns B., Filmer D., \& Patrinos H. (2011 Making schools work. New evidence on accountability reforms (p. 272 Washington, DC: Banco Mundial.

Castillo, B. T. (2011. Medios Masivos de Comunicación: una construcción de la realidad. Pequén, 1(1, 108-119.

Contreras-Salinas, S. (2012. Saber campesino: otra forma de experimentar la escuela rural. Estudios pedagógicos (Valdivia), 38(1,367-381.

De la Maza, G. (2004. Políticas públicas y sociedad civil en Chile: el caso de las políticas sociales (1990-2004. Politica $43,105-148$.

de Sousa Santos, B. (2015. Epistemologies of the south: Justice against epistemicide. Nueva York: Routledge.

de Sousa Santos, B. (2018)Epistemología del Sur: un pensamiento alternativo de alternativas políticas. Geograficando, 14(1, 1-6 https://doi.org/10.24215/2346898Xe032

Dussel, E. (2001)Hacia una filosofía política critica. Bilbao: Desclée de brouwer.

Fardella, C. (2013. Resistencias cotidianas en torno a la institucionalización del modelo neoliberal en las políticas educacionales: El caso de la docencia en Chile. Psicoperspectivas, 12(2, 83-92.

Fardella, C., Sisto, V., Morales, K., Rivera, G., \& Soto, R. (2016: Identidades laborales y ética del trabajo público en tiempos de rendición de cuentas. Psykhe, 25(2,1-11.

Fischer, K. (2009.The influence of Neoliberals in Chile before, during, and after Pinochet. En P. Mirowski \& D. Plehwe (eds.), The road from Mont Pelerin. The making of the neoliberal thought collective (pp. 305-346). Cambridge, Mass.: Harvard University Press.

Fúnez-Flores J.I., \& Phillion J. (2019). A political ontological approach to decolonization of ethnographic research in education. En: Sharma S., \& Lazar A. (eds), Rethinking 21st Century Diversity in Teacher Preparation, K-12 Education, and School Policy (pp. 39-54), vol 7. Springer, Cham. doi:10.1007/978-3-030-02251-8_3

Gantman, E. R. (2017). El desarrollo de los estudios críticos de gestión en los países latinoamericanos de habla hispana. Politica y Sociedad, 54(1), 45.

Gentili, P. (1998). El consenso de Washington y la crisis de la educación en América Latina. Revista Archipiélago, 29, 56-65. 
Gunter, H. M. (2008). Policy and Workforce Reform in England. Educational Management Administration \& Leadership, 36(2), 253-270.

Harvey, D. (1989). From managerialism to entrepreneurialism: the transformation in urban governance in late capitalism. Geografiska Annaler: Series B, Human Geography, 71(1), 3-17.

Hodge, B., \& Coronado, G. (2006). Mexico Inc.? Discourse Analysis and the Triumph of Managerialism. Organization, 13(4), 529-547.

Huergo, J. A., \& Morawicki, K. (2010). Una reescritura contrahegemónica de la formación de docentes. Nómadas, 33, 129-145.

Hypolito, A. M. (2011). Reorganização gerencialista da escola e trabalho docente. Educação: Teoría e prática, 21(38), 59-78.

Ibarra-Colado, E. (2006). ¿Estudios organizacionales en América Latina? Transitando del centro hacia las orillas. Teorias sociales y estudios del trabajo: nuevos enfoques, $24,88$.

Jennings, J. L. (2010). School Choice or Schools' Choice?: Managing in an Era of Accountability. Sociology of Education, 83(3), 227-247.

Kast, M. (1983). Politica económica y desarrollo social en Chile. Santiago: Editorial Nacional Gabriela Mistral.

Maguiña, S. (2007). Industrias culturales: máquina de deseos en el mundo contemporáneo. Lima: Red para el Desarrollo de las Ciencias Sociales en el Perú

Manning, J. (2018). Becoming a decolonial feminist ethnographer: Addressing the complexities of positionality and representation. Management Learning, 49(3), 311-326. https://doi.org/10.1177/1350507617745275

Marañon, B. (2016). De la crisis estructural del patrón de poder mundial, colonial, moderno y capitalista hacia la solidaridad económica y los buenos vivires en América Latina. Cooperativismo \& Desarrollo, 24(109), 1-25.

Mato, D. (2007). Think tanks, fundaciones y profesionales en la promoción de ideas (neo) liberales en América Latina. Cultura y neoliberalismo, 19-42.

Mignolo, W. (2016). El pensamiento des-colonial, desprendimiento y apertura: un manifiesto. Revista Telar (6), 7-38.

Ortiz Gómez, M. G. (2014). El perfil del ciudadano neoliberal: la ciudadanía de la autogestión neoliberal. Sociológica (México), 29(83), 165-200.

Oxhorn, P. (2004). La paradoja del gobierno autoritario: organización de los sectores populares en los ochenta y promesa de inclusión. Política, 43, 57-83.

Pereira, J. M. (2010). O Banco Mundial como ator politico, intelectual e financeiro 1944 - 2008. Rio de Janeiro: Civilização Brasileira.

Sanabria-Rangel, M., Saavedra-Mayorga, J., \& Smida, A. (2015). Los estudios críticos en administración: origen, evolución y posibilidades de aporte al desarrollo del campo de los estudios organizacionales en América Latina. Revista Facultad de Ciencias Económicas: Investigación y Reflexión, 23(1), 209-234.

Schild, V. (2007). Empowering 'Consumer-Citizens` or Governing Poor Female Subjects? The institutionalization of 'self-development' in the Chilean social policy field. Journal of Consumer Culture, 7(2), 179-203. http://doi.o $\mathrm{rg} / 10.1177 / 1469540507077672$

Shah, A. (2005). Public services delivery. Washington: World Bank Publications.

Sierra, N. (2011). Los "gobiernos progresistas" de América Latina. La avanzada del posneoliberalismo. Aportes Andinos. Revista Electrónica de Derechos Humanos, 29, 1-17.

Sisto, V. (2008). La investigación como una aventura de producción dialígca: La relación con el otro y los criterios de validación en la metodología cualitativa contemporánea. Psicoperspectivas, 7, 114-134.

Sisto, V. (2010): La mejora de los Establecimientos Educativos no depende del Director. Revista Docencia, 42(3), 33-35.

Sisto, V. (2011). Nuevo profesionalismo y profesores: una reflexión a partir del análisis de las actuales políticas de 'profesionalización' para la educación en Chile. Signo y Pensamiento, 31(59), 178-192.

Sisto, V. (2012). Identidades Desafiadas: Individualización, Managerialismo y Trabajo Docente en el Chile Actual. Psykhe, 21(2), 35-46. Indexada en Scopus. 
Sisto, V. (2015). ¿Hecho para medir? La práctica pedagógica y la obsesión por la medición. Revista de Educación 10, 8-12.

Sisto, V. (2018). Inclusión "a la Chilena”. La Inclusión Escolar en un contexto de políticas neoliberales avanzadas. Education Policy Analysis Archives. Accepted.

Sisto, V., \& Fardella, C. (2011). Nuevas políticas públicas, epocalismo e identidad: el caso de las políticas orientadas a los docentes en Chile. REU-Revista de Estudos Universitários, 37(1), 123-141.

Sisto, V., \& Zelaya, V. (2013). La Etnografía de Dispositivos y el estudio de los instrumentos de rendición de cuentas como prácticas. Universitas Psychologica, 12(4), 1345-1354.

Sisto, V., Montecinos, C., \& Ahumada, L. (2013). Disputas de significado e identidad: la construcción local del trabajo docente en el contexto de las Políticas de Evaluación e Incentivo al Desempeño en Chile. Universitas Psychologica, 12(1), 173-184.

Varela, E. (2018). La Hegemenonia del Management. Una genealogía del poder managerial. Barranquillas: Ediciones Universidad Simón Bolivar.

\section{Notas}

[1] Los lectores interesados en el marco regulatorio y otros detalles sobre este artículo pueden comunicarse con el autor a través de su e-mail.

* Artículo de investigación científica.

\section{Licencia Creative Commons CC BY 4.0}

Cómo citar: Sisto, V. (2019). Managerialismo versus prácticas locales. La decolonización del discurso managerial desde la vida de la Escuela. Cuadernos de Administración, 32(58). https://doi.org/10.11144/Ja veriana.cao32-58.mvpl 